\title{
RECYCLING OF MIXED PLASTICS WASTE CONTAINING POLYETHYLENE, POLYVINYLCHLORIDE AND POLYETHYLENE TEREPHTHALATE
}

\author{
G.M. Mamoor, Wahab Shahid, Amir Mushtaq, Umer Amjad, Umer Mehmood* \\ Polymer and Process Engineering Department, University of Engineering and Technology, Lahore Pakistan
}

Received 4 February 2012; received in revised form 17 September 2013

\begin{abstract}
This research work was undertaken to investigate the spectroscopic, morphological and rheological properties of polymer blends made of recycled Polyethylene terephthalate (PET), Polyethylene (PE) and Polyvinylchloride (PVC). Different blends of these polymers were made by varying composition of PET. Each recycled blend consisted of recycled polymers and ethylene propylene diene monomer (EPDM) as a compatiblizer. Spectroscopic and morphological characteristics of recycled polymer blends were investigated using Fourier Transform Infrared Spectrometer (FTIR) and Scanning Electron Microscope (SEM) respectively. SEM analysis revealed low miscibility among these three polymers. While rheological properties were investigated using Melt Flow Indexer (MFI). The rheological characterization indicated that melt flow index (MFI) decreases with increase of PET concentration in PE/PET/PVC recycled blends. It was also observed that with increase of PET contents recycled blends show pseudoplastic behavior.
\end{abstract}

Keywords: Mixed plastic;Recycled Blend; Additives; composition; FTIR, SEM;Melt Flow Index.

\section{INTRODUCTION}

It would be hard to imagine a modern society today without plastics. Plastics have found a myriad of uses in fields as diverse as household appliances, packaging, construction, medicine, electronics, and automotive and aerospace components. The reason for its success in replacing traditional materials such as metals, wood and glass in such a diverse range of applications, is the ability to modify its properties to meet a vast array of designers' needs. This, plus the ease with which plastics can be processed, makes them ideal materials for the production of a variety of components.
But the management of plastics waste is one of the major problems facing modern society. A substantial part of public solid waste (MSW) streams is composed of mixed polymers. Polyethylene (PE), polypropylene (PP), polyvinyl chloride (PVC) and Polyethylene terephthalate (PET) are among the most common plastics waste, since they are the most frequently used commercial plastics in our daily lives as well as in industries [1]. A number of approaches are currently being investigated for dealing with post consumer resin. Incineration for the purpose of waste-toenergy recovery is used in a number of

*To whom all correspondence should be addressed. (e-mail: umermehmood@uet.edu.pk) 
countries, which are feared of pollution. Another solution that is currently being developed is pyrolysis. A number of companies are now introducing low levels of plastics waste into hydrocrackers that produce Naphtha, which can then be used as part of feedstock for other applications, including polymerization. A popular solution is the reuse of plastic parts, such as PET drinking bottles in many countries.Recycling of plastics discard is another method of reducing municipal solid waste. The mixed plastics waste can be recycled in the form of blends [2-5]. Recycling of waste plastics as a blend of generic types is attractive since a difficult separations problem is avoided. However, blends of incompatible polymers are frequently very brittle and cannot be considered for many applications. Additives which modify the blend to give it ductility may provide a solution to this problem. In 1972 Paul D.R., Vinson C.E. and Locke C.E suggested that addition of CPE (chlorinated $\mathrm{PE})$ to such a blend generally increases the elongation at break and the energy to break very dramatically with ordinarily some loss in strength and modulus. This approach worked most effectively in blends of high polyethylene and polyvinyl chloride content. Three grades of CPE were studied here which revealed that the specific structure of the CPE molecule is a factor.

The processing of plastics mixtures for recycling has been attempted with some success [6-11]. But the plastics fraction obtained by sorting municipal solid wastes often contains substantial quantity of paper. The reprocessing of such material is very difficult even at paper levels as low as $10 \%$ [12], beside this, the product's appearance is unacceptable due to the inhomogeneity of the mixture, and the mechanical properties are unsatisfactory [13]. In this research work different types of additives were added to improve the mechanical and flow properties of recycled blends.

The trend of reuse of plastics will not only save our environment but also conserve the natural resources because all the plastics are made from crude oil.

\section{EXPERIMENTAL}

\section{Materials}

Basic materials used in these experiments were PE, PVC, PET, and EPDM. Polyethylene terephthalate (PET), Polyethylene (PE) and Polyvinyl chloride (PVC) were obtained from waste soft drink bottles, shopping bags and vinyl pipes respectively. While EPDM was used as compatiblizer and enhance the flow properties as well as impact strength of recycled blends. It was purchased from Continental Carbon India Limited.

\section{Blend Preparation}

Three commonly used plastics such as Polyethylene (PE), Polyvinyl chloride (PVC) and Polyethylene terephthalate (PET) were selected for mixing. These polymers were crushed by using size reduction crusher. The blends of PP/PVC/PET were prepared by using Brabender plasticoder. The mixing time, rotation speed and temperature for the preparation of blend wereas $7 \mathrm{~min}, 80 \mathrm{rpm}$ and $230{ }^{\mathrm{O}} \mathrm{C}$ respectively. Additives were added during processing of blends.

\section{Testing and Characterization}

FTIR spectroscopy technique was executed to characterize the nature of cross linking among the three polymers. The rheological properties were accomplished by melt flow tester (Karg Industritechnik: 3100). Rheological tests were performed according to ASTM D-1238. To observe the morphology of various blends, compression 
moulded samples wereas sputtered with gold in vacuum. These samples were examined by scanning electron microscope (SEM).

\section{RESULTS AND DISCUSSION}

\section{FTIR Analysis}

Fourier Transform Infrared Spectrometer (FTIR) analysis was performed to identify and characterize the different polymers in the waste plastics as well as in the moulded samples.

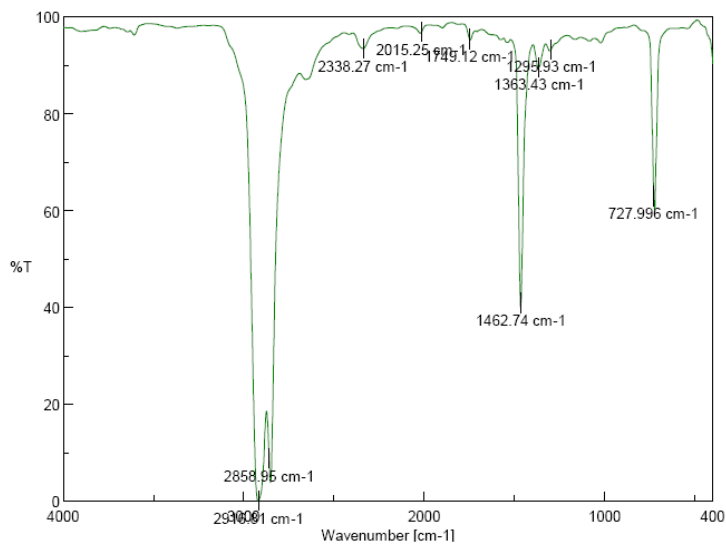

Figure 1: IR Spectra of PE Waste

\section{IR Spectrum of PE Waste}

The spectrum shown in Figure 1 is for crystalline isotactic PE, which is the most common form used in industry. To the low wavenumber side of the strong $\mathrm{CH}_{3}$ deformation mode band near $1375 \mathrm{~cm}^{-1}$, the mid-infrared spectrum of crystalline isotactic PE has many weak characteristic bands, many sharp, which includes bands with maxima near $1330,1310,1255,1220$, 1166, 1103, 999, 975, 841 and $809 \mathrm{~cm}^{-1}$. The relative intensity of bands within the infrared spectrum of crystalline, isotactic PE will be affected to small extents by both the degree of crystallinity and molecular orientation. PE is also commonly copolymerized with ethylene, which gives rise to additional absorption features in the 740 to $710 \mathrm{~cm}^{-1}$ region. A weak $-\mathrm{C}=\mathrm{O}$ band observed near $1745 \mathrm{~cm}^{-1}$ is usually indicative of the presence of an additive.

\section{IR Spectrum of PVC Waste}

Polyvinyl chloride, PVC, is relatively hard, and is often plasticized. Common plasticizers are ortho-dialkyl phthalates, for example, di-n-butyl phthalate, di-(2-ethhyl-hexyl) phthalate. The most readily identifiable mid-infrared absorption features of these phthalates in PVC are the $\mathrm{C}=\mathrm{O}(\mathrm{C}=\mathrm{O}$ stretch $)$ near 1725 $\mathrm{cm}^{-1}$ and the $\mathrm{C}-\mathrm{O}$ bands near $1250 \mathrm{~cm}^{-1}$ and $1100 \mathrm{~cm}^{-1}$ as shown in Figure 2, which are accompanied by a weak sharp, doublet at 1605 and $1575 \mathrm{~cm}^{-1}$. In plasticized PVC the $\mathrm{C}=\mathrm{O}$ and the $\mathrm{C}-\mathrm{O}$ bands may be the most intense in the spectrum. The absorptions in the $\mathrm{CH}$ stretching region will also be much more intense than in unplasticized PVC. The $\mathrm{C}-\mathrm{Cl}(\mathrm{C}-\mathrm{Cl}$ stretch) region of poly (vinyl chloride), PVC, is complex and involves the overlap of several absorption bands arising from differing conformational and configurational forms. Vinylchloride (VC) units may be present in both isotactic and syndiotactic sequences.

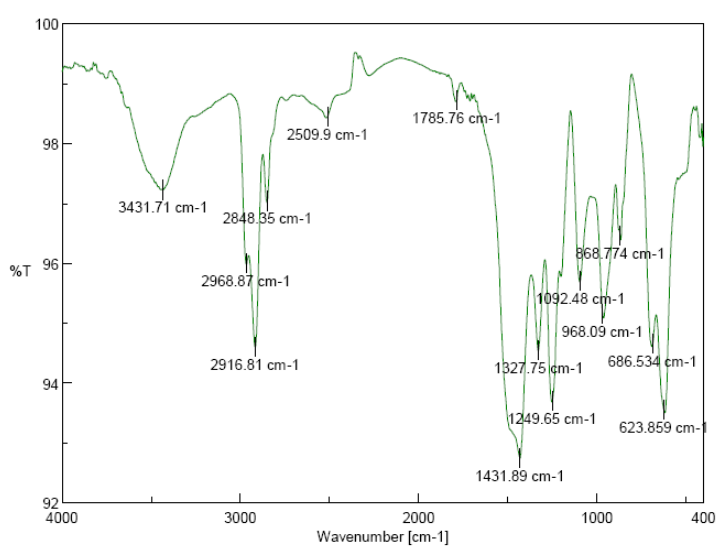

Figure 2: IR Spectra of PVC Waste

$\mathrm{A} \mathrm{Cl}$ atom may exist in either a trans conformation to a $\mathrm{H}$ atom or to a $\mathrm{C}$ atom across the common $\mathrm{C}-\mathrm{C}$ bond; both conformations are possible in both isotactic and syndiotactic PVC. Atactic sequences may also be present. Syndiotactic PVC may 
also be crystalline, and the amorphous to crystalline ratio will also affect the relative intensities of these overlapping $\mathrm{C}-\mathrm{Cl}$ bands.

\section{IR Spectrum of PET Waste}

Polyethylene terephthalate, PET, is manufactured as a polycondensation between ethylene glycol and terephthalic acid or dimethyl terephthalate. The relative intensities of the weak-medium intensity bands, in particular, can differ significantly depending on whether the sample is amorphous or crystalline and/or oriented, and consequently the spectrum can change quite markedly according to a sample's morphology and processing history. The first overtone of the $\mathrm{C}=\mathrm{O}$ near $1728 \mathrm{~cm}^{-1}$ can be observed as weak absorption band near $3410 \mathrm{~cm}^{-1}$ as shown in Figure 3.

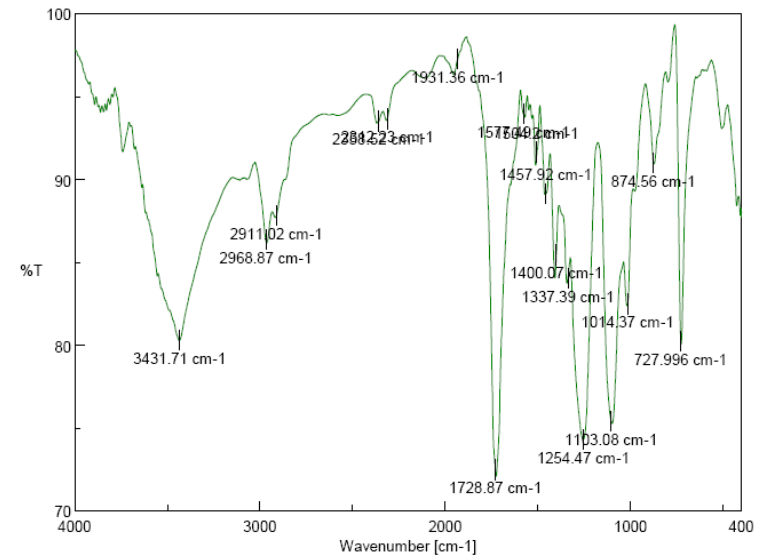

Figure 3: IR Spectrum of PET Waste

In PET, the - $\mathrm{CH} 2-\mathrm{CH} 2-$ unit, arising from the ethylene glycol monomer, can exist in either a trans or a gauche conformation, and while the trans can be present in both the crystalline and amorphous phases, the gauche form is only found in the amorphous phase. These conformers can have distinct bands, for instance, deformation bands associated with the trans conformer occur at 1466, 1335 and $847 \mathrm{~cm}^{-1}$; while, the gauche conformer has bands at 1449, 1368 and 896 $\mathrm{cm}^{-1}$ as shown in Figure 3.

\section{IR Spectrum of Recycled Blend}

IR spectrum of recycled blend is shown in Figure 4. The pair of $\mathrm{C}-\mathrm{O}$ stretching bands near $1270 \mathrm{~cm}^{-1}$ and $1170 \mathrm{~cm}^{-1}$ is a characteristic of most acrylate resins. The lower wavenumber band component is the most intense. The ester $\mathrm{C}=\mathrm{O}$ occurs near $1725 \mathrm{~cm}^{-1}$, and its first overtone can be observed as a weak absorption band near $3450 \mathrm{~cm}^{-1}$. The weak broad band near 733 $\mathrm{cm}-1$ is indicative of three contiguous $\mathrm{CH} 2-$ units, that is $(\mathrm{CH} 2) 3-$; this rocking mode vibration originating from the n-butyl group in the side-chain. The band pattern between $1500 \mathrm{~cm}^{-1}$ and $450 \mathrm{~cm}^{-1}$ is the mid-infrared absorption 'fingerprint' that essentially characterizes poly (n-butyl acrylate). Acrylate esters are frequently copolymerized.

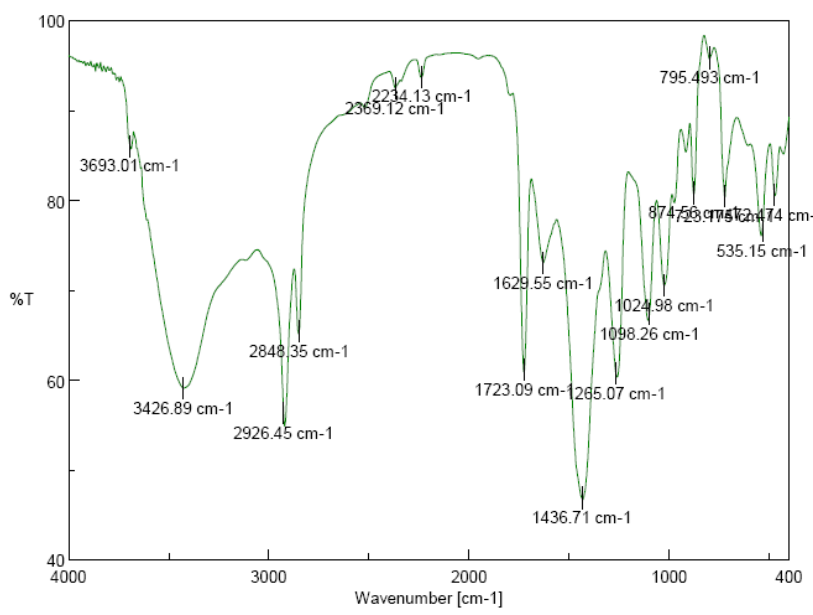

Figure 4: IR Spectrum of Recycled Blend

\section{Morphology of Recycled Blend}

SEM micrograph of recycled blend is shown in Figure 5. It shows that the dispersed phase is easy to be pulled-off from the blend and leaves uneven surface, indicating low immiscibility among three polymers (Figure 5 a). Because of the high interfacial tension, the morphology of recycled blend is not stable. Coalescence readily occurs in the molten state. In melt mixing of immiscible polymer blends, the 
disperse phase is first stretched into threads (Figure $5 \mathrm{~b}$ ) and then breaks into droplets, which can coalesce together into large droplets (Figure $5 \mathrm{c}$ ). The balance of these processes determines the final dispersed particle sizes.
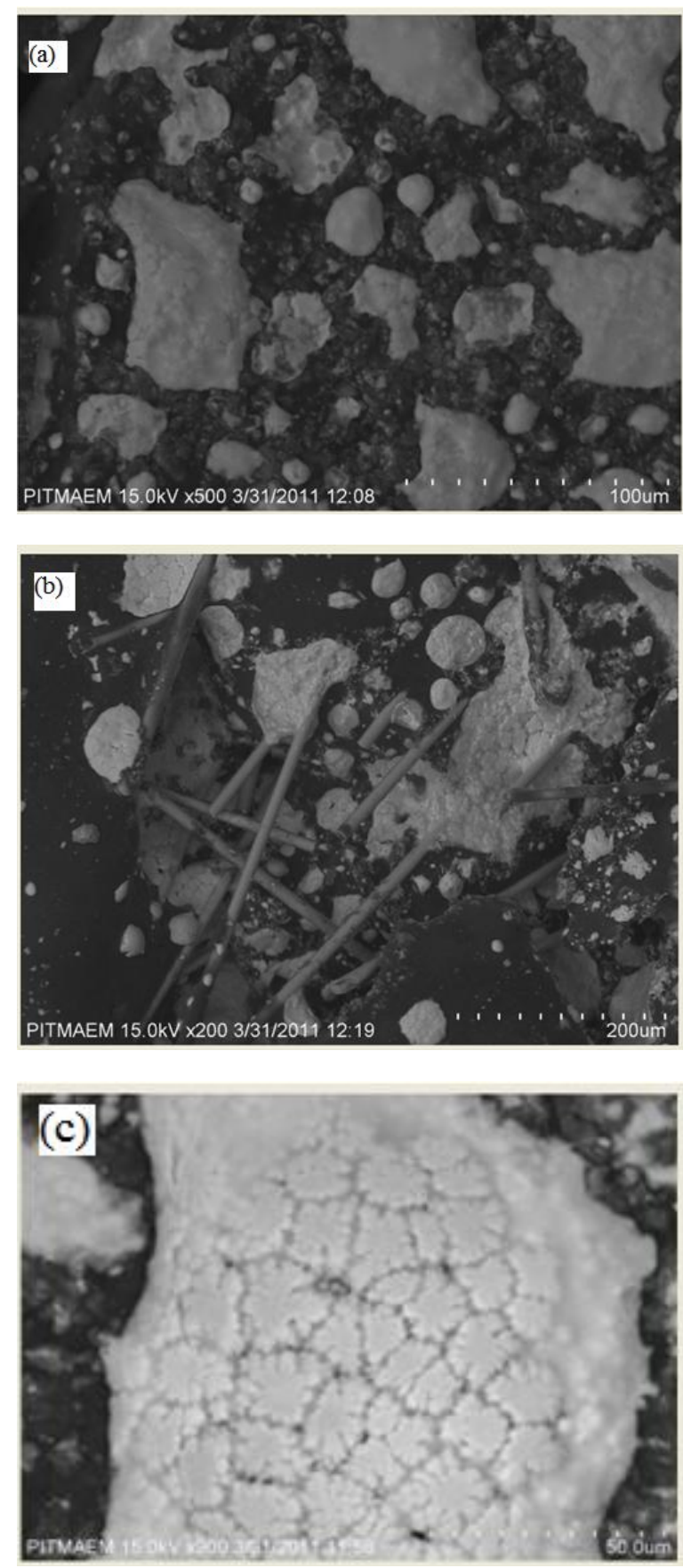

Figure 5: SEM Micrograph of Recycled PET/PVC/PE (33/33/34) Blend, (a) Low Immiscibility Between Polymers, (b) Stretching of Disperse Phase, (c) Formation of Large Droplet

\section{Rheological Properties}

Rheological measurements are very important for quality control of raw materials, optimization of manufacturing processes and forecasting the performance of a material.

The melt flow index is an indication of the flow ability of a polymer melts. Figure 6 shows the relationship between PET contents in recycled blend and MFI. It is evident from the figure that the melt flow index (MFI) decreases with increase in PET concentration. Figure also demonstrates that melt flow index is increasing function of load. Because the molecular layers of polymers become more slippery with increasing heat and shear stress. Moreover as load increases, force that is being applied on the melt present in the heated barrel increases that pushes the melt rapidly through the barrel and hence the melt flow rate is increased.

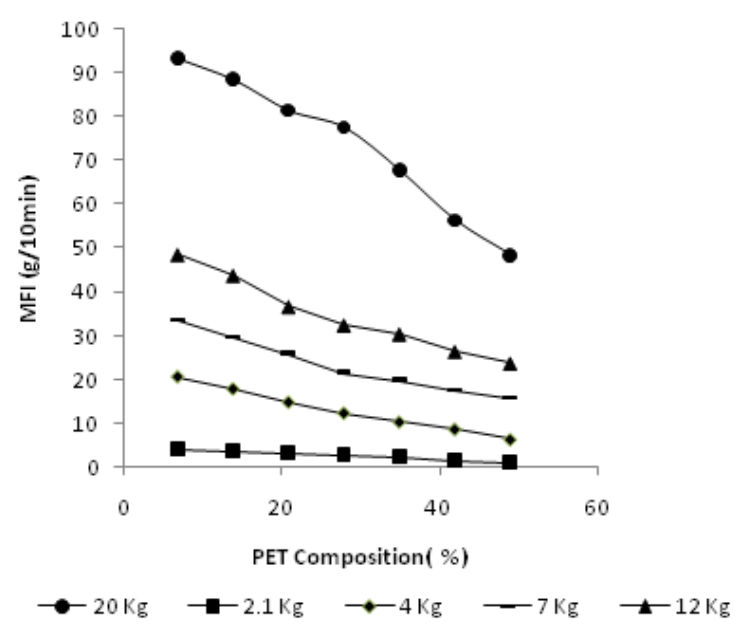

Figure 6: MFI as a Function of PET Composition

Shear stress and strain rate can be calculated by using equation 1 and 2 respectively 
$\tau_{w}=\frac{R_{N} F}{2 \pi R_{P}^{2} L_{N}}$

$\gamma_{a}=\frac{4 Q}{\pi R_{N}^{3}}$

Where $R_{N}$ is radius of nozzle, $L_{N}$ is nozzle length $R_{P}$ is piston radius, $Q$ is flow rate and $\mathrm{F}$ is test load.

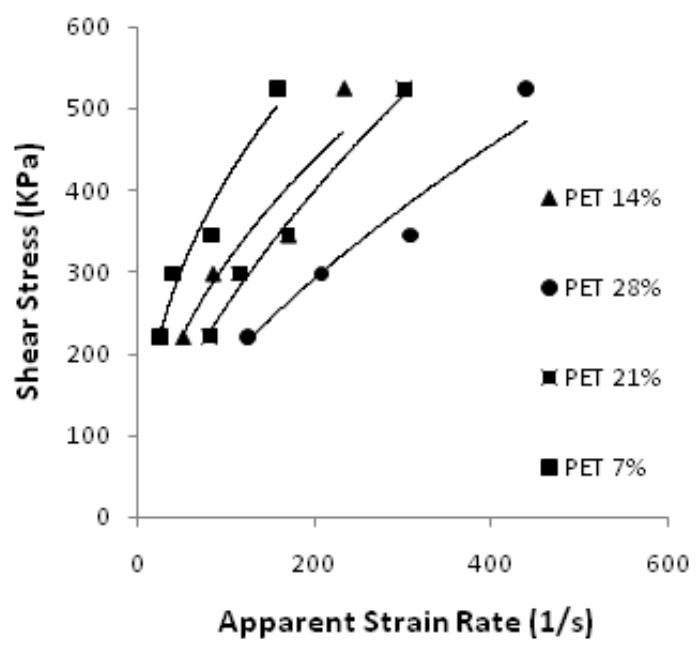

Figure 7: Curves Demonstrating PseudoPlasticity of Recycled Blend by Varying Composition of PET in Recycled Blend

Figure 7 clearly indicates behavior of material as pseudoplastic with yield stress. Results also show that at constant strain rate more stress is required for recycled blend having more PET contents. Because PET resists the flow and elongation, therefore for constant strain, stress requirement is lower for lower PET contents recycled blend. Figure-8 demonstrates that power law parameter decreases with increase in PET contents which implies recycled blends having larger amount of PET show more pronounced shear thinning characteristics.

Viscosity can be calculated from equation 3

$\eta_{a}=m \gamma^{n-1}$

Where $\boldsymbol{\eta}_{\boldsymbol{a}}$ is the apparent viscosity.
This figure also demonstrates that at constant strain rate viscosity increases with increase in PET contents because PET provides resistance to flow.

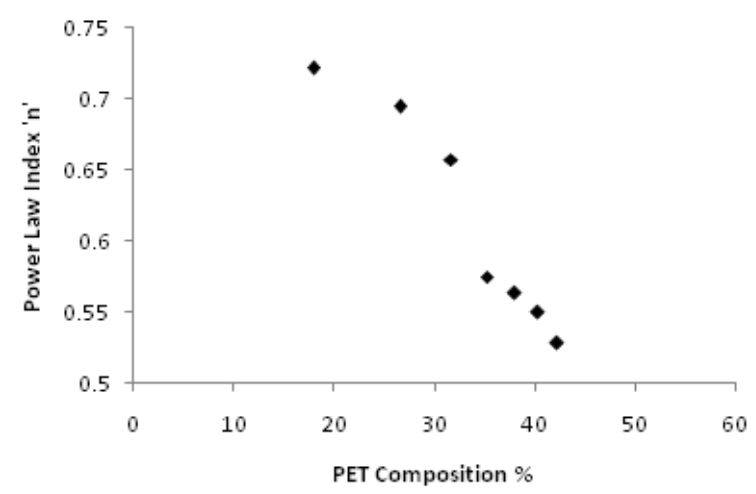

Figure 8: Variation in Power Law Index with PET Concentration

For the case of flow of polymer through circular die, a correction is normally applied to take into account the pseudoplastic nature of the melt which implies that the assumed parabolic profile in the die actually illustrates more plug flow behavior. This correction is generally expressed as

$\tau_{\text {true }}=\frac{4 Q}{\pi R^{3}} \frac{3 n+1}{4 n}$

Curves obtained after applying correction factor are also shown in Figure 10.

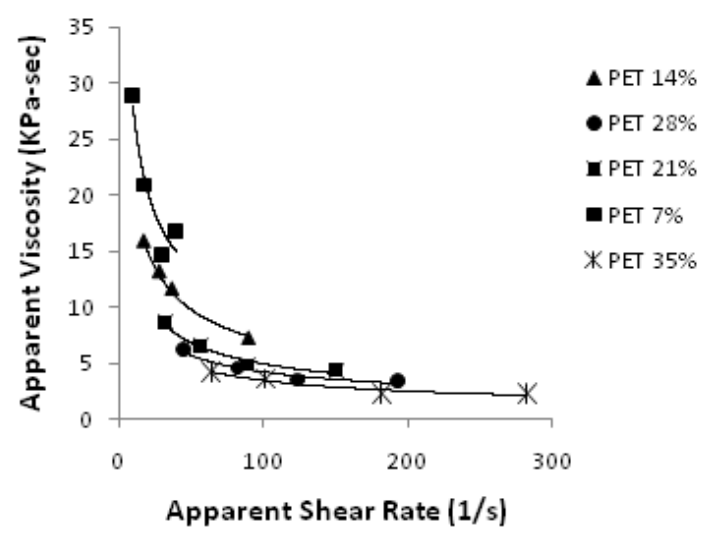

Figure 9: Viscosity as a Function of Strain Rate 


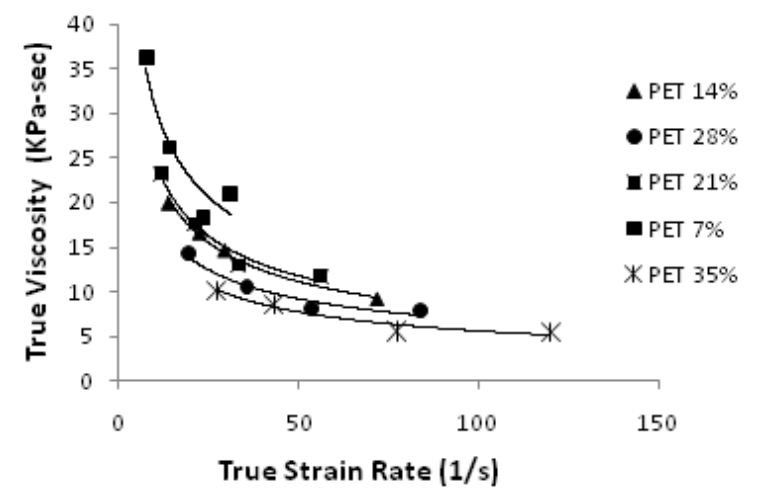

Figure 10: True Viscosity as a Function of True Strain Rate

\section{CONCLUSION}

FTIR analysis of recycled blend exhibits no extra peaks for the blends, neither any shifts or changes in the absorption bands of the carbonyl, hydroxyl and carboxylic groups of PET, nor any changes for PE and PVC which indicate the absence of any specific interaction or chemical reaction between these polymers. Micrographical studies shows that the dispersed phase is easy to be pulled-off from the blend and leaves uneven surface, indicating low miscibility among three polymers. Because of the high interfacial tension, the morphology of recycled blend is not stable. Coalescence readily occurs in the molten state. While rheological analysis shows an increase in PET concentration causes decrease in power law parameter which implies that recycled blends show more pronounced shear thinning characteristic.

\section{ACKNOWLEDGEMENT}

The authors are thankful to the Department of Polymer And Process Engineering, University of Engineering and Technology, Lahore, Pakistan for the laboratory support.

\section{REFEENCES}

[1] Paul D.R., Vinson C.E. and Locke C.E., The potential for reuse of plastics recovered from solid wastes, Polym. Eng. Sci., 12, 157166 (1972).

[2] Scheir J., Polymer Recycling, John Wiley, England, (1998).

[3] Ghaffar A. and Scott, G., Polymer blends-I: Mechanical and morphological behavior of PE/ PVC blends, Eur. Polym. J., 14, 631-638 (1978).

[4] Utraki L.A., Commercial Polymer Blends, Chapman \& Hall, Canada, 469-485 (1998).

[5] Fang Z., Xu C., Bao, S. and Zhao Y., In situ cross-linking and its synergism with compatibilization in PVC/PE blends, Polymer, 38, 1, 131-133 (1997).

[6] Ha C.S., Park H.D., and Cho W.J., Compatibilizers for recycling of the plastic mixture wastes, J. Appl. Polym. Sci., 76, 1048-1053 (2000).

[7] Ajji A., Morphology and mechanical properties of virgin and recycled PE/PVC blends, Polym. Eng. Sci., 35, 64-71 (1995).

[8] Hajian M., Sadremohaghegh C., and Scott G., Polymer blends IV. Solid phase dispersants synthesized by a mechanochemical procedure, Eur. Polym. J., 20, 135-138 (1984)

[9] Blom H.P., Teh J.W., and Rudin A., PP/PE blends IV: Characterization and compatibilization of blends of postconsumer resin with virgin PP and HDPE, J. Appl. Polym. Sci., 70, 2081-2095 (1998). 
[10] Boneli C.M.C., Martins A.F., Mano E.B., and Beatty C.L., Effect of recycled polypropylene on PP/HDPE blends; J. Appl. Polym. Sci., 80,1305-1311 (2001).

[11] Vivier, T. and Xantos, M., Peroxide modification of multicomponent polymer blend with potential applications, J. Appl. Polym. Sci., 54, 569-575 (1994).

[12] Mathiasson A., Klason C., Kubat J., and Skov H., Hydrolytic treatment of plastics waste contaminated with paper, Resources, Conservation and Recycling, 2, 57-67 (1988).

[13] Klason C., and Kubat J., Improving the homogeneity and mechanical properties of plastics waste contaminated by paper using a hydrolytic treatment, Conservation \& Recycling, 10, 169-175 (1987). 